\title{
Multiplex polymerase chain reaction to diagnose bloodstream infections in patients after cardiothoracic surgery
}

Kevin Pilarczyk ${ }^{1,3}$, Peter-Michael Rath ${ }^{4}$, Joerg Steinmann ${ }^{4,5}$, Matthias Thielmann ${ }^{3}$, Stephan A. Padosch², Max Dürbeck ${ }^{3}$, Heinz Jakob ${ }^{3}$ and Fabian Dusse ${ }^{2,3^{*}}$

\begin{abstract}
Background: Sepsis and other infectious complications are major causes of mortality and morbidity in patients after cardiac surgery. Whereas conventional blood culture (BC) suffers from low sensitivity as well as a reporting delay of approximately 48-72 h, real-time multiplex polymerase chain reaction (PCR) based technologies like "SeptiFast" (SF) might offer a fast and reliable alternative for detection of bloodstream infections (BSI). The aim of this study was to compare the performance of SF with BC testing in patients suspected of having BSI after cardiac surgery.
\end{abstract}

Methods: Two hundred seventy-nine blood samples from 169 individuals with suspected BSI were analyzed by SF and BC. After excluding results attributable to contaminants, a comparison between the two groups were carried out. Receiver operating characteristic (ROC) curves were generated to determine the accuracy of clinical and laboratory values for the prediction of positive SF results.

Results: $14.7 \%(n=41)$ of blood samples were positive using SF and 17.2\% $(n=49)$ using BC (n.S. [ $p>0.05])$. In six samples SF detected more than one pathogen. Among the 47 microorganisms identified by SF, only 11 (23.4\%) could be confirmed by BC. SF identified a higher number of Gram-negative bacteria than BC did (28 vs. $\left.12, X^{2}=7.97, p=0.005\right)$. The combination of $B C$ and SF increased the number of detected microorganisms, including fungi, compared to $B C$ alone ( 86 vs. $\left.49, X^{2}=13.51, p<0.001\right)$. C-reactive protein (CRP) $(21.7 \pm 11.41$ vs. $16.0 \pm 16.9 \mathrm{mg} / \mathrm{dl}, p=0.009$ ), procalcitonin ( $28.7 \pm 70.9$ vs. $11.5 \pm 30.4 \mathrm{ng} / \mathrm{dl}, p=0.015)$, and interleukin 6 (IL 6) $(932.3 \pm 1306.7$ vs. $313.3 \pm 686.6 \mathrm{pg} / \mathrm{ml}, p=0.010)$ plasma concentrations were higher in patients with a positive SF result. Using ROC analysis, IL-6 (AUC 0.836) and CRP (AUC 0.804) showed the best predictive values for positive SF results.

Conclusion: The SF test represent a valuable method for rapid etiologic diagnosis of BSI in patients after cardiothoracic surgery. In particular this method applies for individuals with suspected Gram-negative blood stream. Due to the low performance in detecting Gram-positive pathogens and the inability to determine antibiotic susceptibility, it should be used in addition to BC only (Pilarczyk K, et al., Intensive Care Med Exp ,3(Suppl. 1):A884, 2015).

Keywords: Blood stream infection, Blood culture, Real time multiplex polymerase chain reaction

\footnotetext{
* Correspondence: fabian.dusse@uk-koeln.de

${ }^{2}$ Department of Anaesthesiology and Intensive Care Medicine, University

Hospital of Cologne, Kerpener Str. 62, 50937 Köln, Germany

${ }^{3}$ Department of Thoracic and Cardiovascular Surgery, West German Heart

and Vascular Center Essen, University Hospital Essen, University of

Duisburg-Essen, Essen, Germany

Full list of author information is available at the end of the article
}

(c) The Author(s). 2019 Open Access This article is distributed under the terms of the Creative Commons Attribution 4.0 International License (http://creativecommons.org/licenses/by/4.0/), which permits unrestricted use, distribution, and reproduction in any medium, provided you give appropriate credit to the original author(s) and the source, provide a link to the Creative Commons license, and indicate if changes were made. The Creative Commons Public Domain Dedication waiver (http://creativecommons.org/publicdomain/zero/1.0/) applies to the data made available in this article, unless otherwise stated. 


\section{Background}

Nosocomial infections represent the main non-cardiac complication after cardiovascular surgery and are associated with substantial morbidity, increased mortality, prolonged hospitalization and, eventually, economic burden $[2,3]$. Respiratory tract infections account for more than half of all nosocomial infections after open heart surgery followed by surgical site infections and bloodstream infections (BSI) with a prevalence of approximately $20 \%$ [4]. Patients with BSI have a 4.2-fold increased risk of death, compared with non-infected patients [5]. Environmental contamination could be responsible of nosocomial infection acquisition and diffusions of multi drug resistance microorganisms (MDR) $[6,7]$. Current guidelines highlight the importance of rapid administration of the most appropriate antimicrobial treatment to improve the survival of patients with suspected BSI and sepsis [8]. This is of special importance in respect of the problem of the ongoing antimicrobial resistance. The "gold standard" for the diagnosis of BSI is blood culture (BC) with pathogen identification and consecutive drug susceptibility testing. However, this process regularly requires at least 24 to $72 \mathrm{~h}$. Sensitivity of BC is low due to uncultivable or fastidious microorganisms, polymicrobial or invasive fungal infections, or administration of anti-infectives prior to blood sampling [9]. Lee et al. reported that $73 \%$ of pathogens were detected with the first blood cultures, $90 \%$ with two, $98 \%$ with three, and 99.8\% with four different consecutive blood cultures [10]. In addition, discrimination between infection and potential contamination is sometimes difficult. Thus, there is an urgent need to establish a rapid, sensitive, and specific method for detection of bacterial and fungal pathogens to improve management of patients with suspected BSI. PCR-based technologies have emerged over the last two decades and could represent an appropriate diagnostic tool in terms of sensitivity and speed of pathogen detection, in particular in life-threatening infections.

The LightCycler ${ }^{\circ}$ SeptiFast (SF) is a multi-pathogen probe-based real-time PCR system targeting DNA sequences of 25 commonly observed bacteria and fungi present in blood samples within a few hours. However, data about the impact of PCR-based diagnostics on clinical decision-making process and modification of empirical antimicrobial therapy are very limited. A recently published prospective randomized trial demonstrated that in addition to a reduction in the time required for initial pathogen identification, the use of PCR was clearly able to reduce the time required for therapy modification from 38 to $19 \mathrm{~h}$, however without reaching statistical significance [11]. Currently, there are no data about the accuracy and the impact of PCR based detection of BSI in patients undergoing cardiac surgery. Therefore, the aim of our study was to compare the performance of SF with conventional BC system in patients suspected of having BSI after cardiothoracic surgery.

\section{Methods \\ Patients}

In this retrospective observational study, data were collected between January 2009 and February 2013 on all consecutive patients with SF at our Intensive Care Unit (ICU), Department of Thoracic and Cardiovascular Surgery, West German Heart Centre Essen, Germany, in our institutional database. The diagnosis of the suspected BSI was made by clinical judgment by the treating physicians on basis of the occurrence of systemic inflammatory response syndrome (SIRS)/Sepsis criteria [8]. The decision of using SF was made either by the treating physicians or the infectious disease specialists. Data analysis was performed after the collection period. The study was approved by the Institutional Review Board according to the Declaration of Helsinki. All of the patients had previously granted permission for use of their medical records for research purposes. This written informed consent was obtained within the preoperative surgical written and verbal information conversation.

Patients were considered for inclusion in the study only if the met the following criteria:

(I) Suspected bacterial or fungal BSI

(II) Collection of paired blood samples for SF and at least two sets of BCs (two aerobic and two anaerobic bottles) from a peripheral vein or a central venous line at the same time point (within two hours)

The BC and SF results were compared separately by positivity of samples and by detected species of microorganisms/isolates.

\section{Blood cultures}

Blood samples (at least two pairs of aerobic and anaerobic BC bottles, volume of $8-10 \mathrm{~mL}$ each) were collected by sterile venipuncture or from a central venous catheter $(\mathrm{CVC})$ after disinfection of the connector and inserted into aerobic and anaerobic bottles and were sent to the laboratory. Samples then were incubated into the Bactec 9240 Plus (Becton Dickinson, Heidelberg, Germany), an automated microbial detection platform based on the colorimetric detection of $\mathrm{CO}_{2}$ produced by growing microorganisms. $\mathrm{BC}$ bottles were incubated up to seven days. In case of a positive signal on the Bactec instrument, $10 \mu \mathrm{L}$ blood from aerobic blood culture was plated onto chocolate agar, blood agar, MacConkey agar, chromogenic yeast medium, and, if anaerobic bottle were positive, additionally onto two solid anaerobic media (Beerens and Schaedler agar; all from Oxoid, 
Wesel, Germany). Identification and susceptibility testing was performed according to the EUCAST (European Committee on Antimicrobial Susceptibility Testing) standard using the matrix-assisted laser desorption/ ionization time-of-flight mass spectrometry VITEK MS, the VITEK2 (both bioMérieux, Nürtingen, Germany) and WalkAway MicroScan (Beckman Coulter, Krefeld, Germany) [12].

\section{SeptiFast}

The LightCycler ${ }^{\circ}$ SeptiFast test M Grade (Roche Molecular Systems, Mannheim, Germany) is an in vitro nucleic acid amplification test for the detection of bacterial as well as fungal DNA in human blood. It allows the identification of 25 bacterial and fungal species (see Table 1), being responsible for approximately $90 \%$ of all bloodstream infections. SF is the first real-time PCR-based system to be awarded a Conformité Européenne (CE) mark for pathogen detection and identification in suspected bloodstream infection. The analytical sensitivity of the assay, as indicated by the manufacturer, is between three and 100 colony forming units $(\mathrm{CFU}) / \mathrm{ml}$, depending on the microorganism. Following the manufacturer's instructions, DNA was extracted and was amplified by the LightCycler in three individual reactions (Gram-positive bacteria, Gram-negative bacteria, and fungi). To exclude false-negative results the test includes an internal control, provided by the SeptiFast kit. PCR products were simultaneously detected by fluorescence and melting temperature analysis, using specific hybridization probes and identification software.

Discrimination between infection and contamination in BC Coagulase-negative staphylococci (CoNS), Streptococcus spp., Corynebacterium spp., or Bacillus spp. are frequent contaminants of BCs. To discriminate between true BSI and contamination, an algorithm based on a previous

Table 1 Analytical spectrum of the LightCycler ${ }^{\circledR}$ SeptiFast test

\begin{tabular}{lll}
\hline $\begin{array}{l}\text { Gram-positive } \\
\text { bacterial species }\end{array}$ & $\begin{array}{l}\text { Gram-negative } \\
\text { bacterial species }\end{array}$ & Fungal species \\
\hline Staphylococcus aureus & Escherichia coli & Candida albicans \\
Staphylococcus epidermidis & Klebsiella pneumoniae & Candida tropicalis \\
Staphylococcus haemolyticus & Klebsiella oxytoca & Candida parapsilosis \\
Streptococcus pneumoniae & Serratia marcescents & Candida krusei \\
Streptococcus pyogenes & Enterobacter cloacae, & Candida glabrata \\
Streptococcus agalactiae & Proteus mirabilis & Aspergillus fumigatus \\
Streptococcus mitis & Pseudomonas aeruginosa & \\
Enterococcus faecium & Acinetobacter baumannii & \\
Enterococcus faecalis & Stenotrophomonas & \\
& maltophilia &
\end{tabular}

For coagulase-negative staphylococci and streptococci, a semiquantitative analytical cut-off value has been set by the manufacturer for distinguishing between true pathogens and contaminants from the skin flora study was applied. A true BSI was considered if the patient has at least three SIRS criteria or two SIRS criteria and a CVC or other prosthetic material [13]. Positive findings for fungi were interpreted according to the European Organization for Research and Treatment of Cancer/Invasive Fungal Infections Cooperative Group and the National Institute of Allergy and Infectious Diseases Mycoses Study Group diagnostic classification of fungal infections [14].

Discrimination between infection and contamination in SF Isolates identified by PCR were considered to be pathogens or contaminants using a modified algorithm, combining microorganism pathogenicity, interpretation of blood culture results, and clinical, laboratory, and microbiological data [15]. The threshold of the SeptiFast software, based on the bacterial DNA amount, excluded CoNS and streptococci from the positive results and considered them contaminants. Fungal pathogens were categorized as described above.

\section{Statistical analysis}

Statistical analyses were performed with SPSS Statistics 19 (IBM, Chicago, IL). Continuous data were expressed as median $\pm 95 \%$ confidence interval (CI); categorical data were expressed as percentage. Comparisons between two groups were carried out using unpaired Student's t-test for normally or the Mann-Whitney Rank Sum Test for non-normally distributed data. Multiple groups were compared with ANOVA. Univariate analysis was performed on the quantitative variables using the Student t-test or Mann-Whitney test and on the qualitative variables using the $\mathrm{Chi}^{2}$ test of Fisher's exact test.

To measure the sensitivity and specificity of laboratory and clinical data at different cut-off values, a conventional receiver operating characteristic (ROC) curve was generated. All variables showing a $p$-value of less than 0.1 between the two groups using Student t-test, Mann-Whitney test, $\mathrm{Chi}^{2}$ test of Fisher's exact test were selected for ROC analyses. The optimal cut-off concentration was defined by the highest Jouden index ( $J$ = sensitivity + specificity -1$)$. Statistical significance was assumed for a $p$-value $<0.05$.

\section{Results}

During the study period, 279 matched blood samples from 169 patients suspected of having BSI were analyzed with conventional BC and SF. Out of these, 78\% (132/ 169) were under antibiotic treatment at this time. Contaminants were significantly more frequent among blood cultures than SeptiFast (23 [8.2\%] vs. 2 [0.71\%], $p<0.001$ ).

After excluding contaminants, SF identified 47 , while BC identified 49 episodes of BSI $\left(X^{2}=0.05, P=0.822\right)$. As illustrated in Fig. 1, SF exclusively detected 36 pathogens 


\section{9 samples from 169 patients}

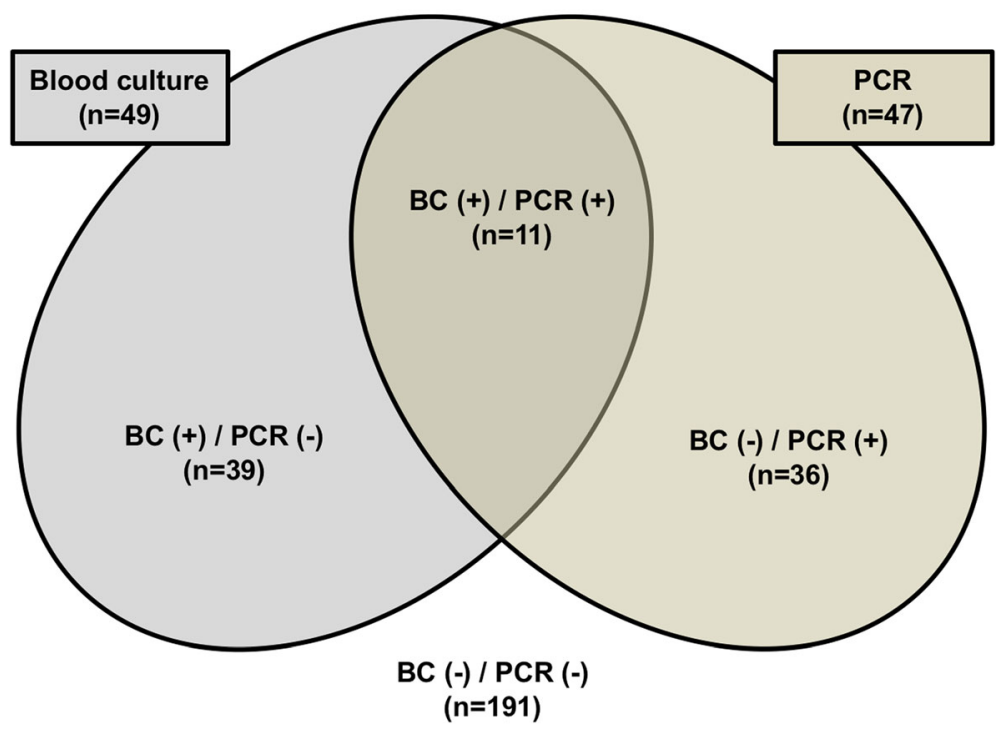

Fig. 1 Number of detected microorganisms classified as infection in PCR, blood culture

that were missed by $\mathrm{BC}$, whereas $\mathrm{BC}$ detected 39 pathogens in SF-negative individuals. Thus, 86 positive episodes of BSI were identified with the combination of both methods, being significantly higher than with SF or BC alone $\left(X^{2}=10.86, p<0.001\right.$ for $\mathrm{SF}$ and $\chi^{2}=12.35, p<0.001$ for $\mathrm{BC})$. BC analyses resulted in $51 \%$ sensitivity, $83 \%$ specificity, $46.7 \%$ positive predictive value (PPV), and $54.1 \%$ negative predictive value (NPV) whereas SF resulted in $51 \%$ sensitivity, $84 \%$ specificity, $46.4 \%$ PPV, and $54.4 \%$ NPV. s.

With $\mathrm{BC}$, CoNS was the most frequently detected agent $(13 / 49,26.5 \%)$ followed by E. faecium (10/49, $20.4 \%$ ) and Candida spp. (9/49, 18.4\%). In contrast, the most frequently observed pathogen in SF was Candida spp. (9/47, 19.1\%) followed by Enterobacter spp. (8/47) and Klebsiella spp. (7/49, 14.3\%).

SF identified 7/33 (21\%) Gram-positive bacteria, 28/35 (8\%) Gram-negative, and 12/67 (67\%) fungi, while BC identified 28/33 (85\%), 12/35 (34\%), and 9/18 (50\%), respectively (Table 2 ).

Gram-negative detection rate was significantly higher with $\mathrm{SF}$ than with $\mathrm{BC}\left(\mathrm{X}^{2}=14.93 ; p<0.001\right)$, but for fungi, the difference to $B C$ was not relevant $\left(X^{2}=1.03\right.$; $p=0.3$ ). In contrast, detection rate of Gram-positive bacteria was significantly higher with $\mathrm{BC}$ compared to SF $\left(x^{2}=25,09 ; p<0.001\right)$.

SF identified 36 pathogens that were not found in $\mathrm{BC}$, while $B C$ detected 39 pathogens in SF negative specimens. Microbial strains exclusively identified by SF were: $E$. coli $(n=3)$, Klebsiella spp. $(n=6)$, E. faecium $(n=4)$, Enterobacter spp. $(n=7)$, E. faecalis $(n=1), P$. aeruginosa $(n=3)$,
A. fumigatus $(n=3), C$. spp. $(n=6), S$. marcescens $(n=3)$, S. maltophilia $(n=1)$. BC detected the following pathogens in SF negative samples: CoNS $(n=13)$, E. faecium $(n=10)$, C. albicans $(n=6)$, S. marcesens $(n=3)$, Klebsiella spp. $(n=2), S$. aureus $(n=1), E$. coli $(n=1)$, other Streptococcus spp. $(n=1)$, E. faecalis $(n=1)$, M. morganii $(n=1)$. Polymicrobial infections were observed in seven patients. Five episodes were detected by SF; while $\mathrm{BC}$ identified multiple agents in only four specimens.

\section{Predictors for SF positivity}

Several variables of the patients with and without pathogen identification in SF and BC were compared, respectively (Table 3). Whereas baseline demographics, gender, BMI, EuroScore- 2 and SAPS and TISS on the day of admission on ICU as well as type of surgery did not differ between the two groups, patients with positive PCR were significantly younger than patients with negative PCR (57 years [51.7-68.0] vs. 68.0 [64.3-70.0], $p=0.01$ ). In addition, prevalence of acute kidney Injury (AKI) with need for renal replacement therapy (RRT) was higher in SF positive patients $(76 \%$ vs. $53 \%, p=0.01)$.

Laboratory markers of inflammation differed significantly between groups: $C$-reactive protein (CRP) $(21.7 \mathrm{mg} / \mathrm{dl} \pm 11.41$ vs. $16.0 \pm 16.9, p=0.009)$, procalcitonin (PCT) $(6.6 \mathrm{ng} / \mathrm{ml}$ [2.7-16.4] vs. 3.1 [2.3-4.7], $p=0.015)$ as well as interleukin 6 (IL-6) $(235.0 \mathrm{pg} / \mathrm{ml}$ [83.5-1582.2] vs. 72.3 [46.5-104.7], $p=0.010)$ were significantly higher in patients with positive SF result. In contrast, patients with negative PCR had a 


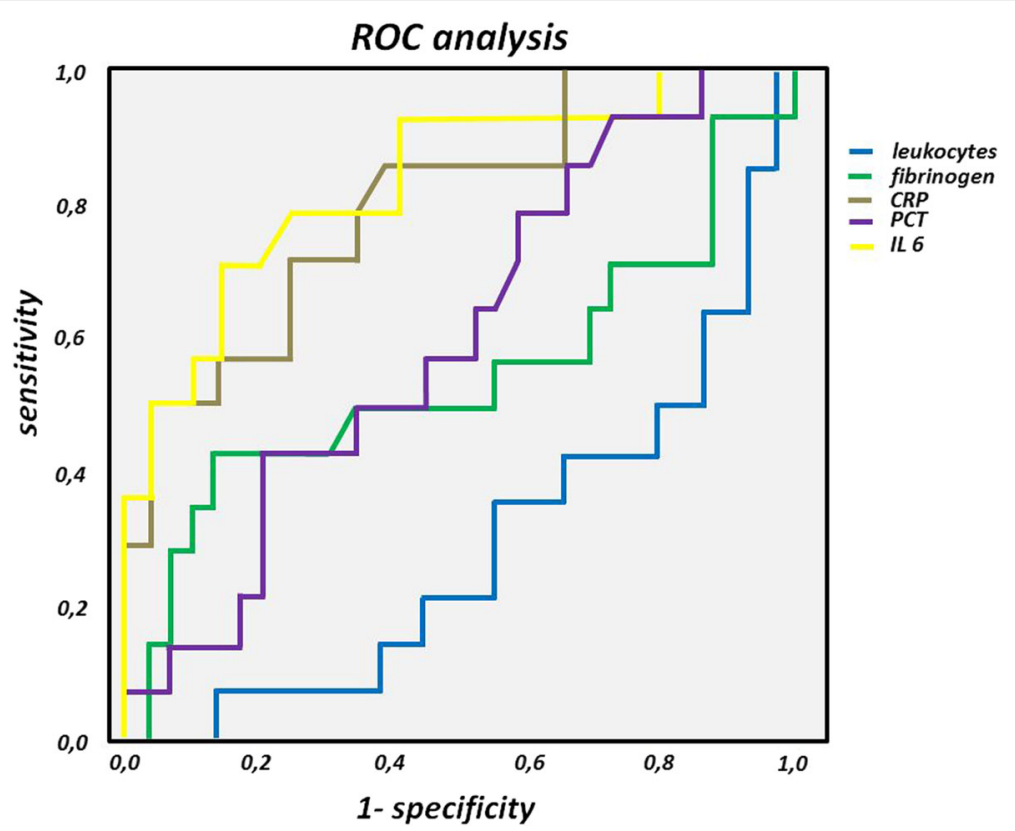

Fig. 2 Receiver operator characteristic (ROC) curve for the prediction of SF positivity.

Table 2 Detected microorganisms after exclusion of contaminations

\begin{tabular}{|c|c|c|c|c|c|c|}
\hline \multirow[b]{2}{*}{ Pathogens } & \multicolumn{6}{|c|}{ Number of isolates } \\
\hline & Total & Detected by PCR & Detected by $\mathrm{BC}$ & PCR pos/BC pos & PCR pos/BC neg & PCR neg/BC pos \\
\hline Gram-positive bacteria & 33 & $7(21 \%)$ & $28(85 \%)$ & $2(6 \%)$ & $5(15 \%)$ & $26(79 \%)$ \\
\hline Staphylococcus aureus & 2 & $1(50 \%)$ & $2(100 \%)$ & $1(50 \%)$ & $0(0 \%)$ & $1(50 \%)$ \\
\hline CONS & 13 & $0(0 \%)$ & $13(100 \%)$ & $0(0 \%)$ & $0(0 \%)$ & $13(100 \%)$ \\
\hline Streptococcus pneumoniae & 0 & 0 & 0 & 0 & 0 & 0 \\
\hline Other Streptococcus spp. & 1 & $0(0 \%)$ & $1(100 \%)$ & $0(0 \%)$ & $0(0 \%)$ & $1(100 \%)$ \\
\hline Enterococcus faecalis & 3 & $2(67 \%)$ & $2(67 \%)$ & $1(33 \%)$ & $1(33 \%)$ & $1(33 \%)$ \\
\hline Enterococcus faecium & 14 & $4(29 \%)$ & $10(71 \%)$ & $0(0 \%)$ & $4(29 \%)$ & $10(71 \%)$ \\
\hline Gram-negative bacteria & 35 & $28(80 \%)$ & $12(34 \%)$ & $6(17 \%)$ & $22(63 \%)$ & $7(20 \%)$ \\
\hline Escherichia coli & 5 & $4(80 \%)$ & $2(40 \%)$ & $1(20 \%)$ & $3(60 \%)$ & 1 (20\%) \\
\hline Pseudomonas aeruginosa & 5 & $5(100 \%)$ & $2(40 \%)$ & $2(40 \%)$ & $3(60 \%)$ & $0(0 \%)$ \\
\hline Enterobacter cloacea & 8 & $8(100 \%)$ & $1(13 \%)$ & $1(13 \%)$ & $7(88 \%)$ & $0(0 \%)$ \\
\hline Klebsiella pneumonia & 9 & $7(78 \%)$ & $3(33 \%)$ & $1(11 \%)$ & $6(67 \%)$ & $2(22 \%)$ \\
\hline Stenotrophomonas maltophilia & 1 & $1(100 \%)$ & $0(0 \%)$ & $1(100 \%)$ & $0(0 \%)$ & $0(0 \%)$ \\
\hline Corynebacterium spp & 0 & - & 0 & - & - & 0 \\
\hline Morganella morganii & 1 & - & $1(100 \%)$ & - & - & $1(100 \%)$ \\
\hline Serratia marcensens & 6 & $3(50 \%)$ & $3(50 \%)$ & $0(0 \%)$ & $3(50 \%)$ & $3(50 \%)$ \\
\hline Fungi & 18 & $12(67 \%)$ & $9(50 \%)$ & $3(17 \%)$ & $9(50 \%)$ & $6(17 \%)$ \\
\hline Aspergillus fumigatus & 3 & $3(100 \%)$ & $0(0 \%)$ & $0(0 \%)$ & $3(100 \%)$ & $0(0 \%)$ \\
\hline Candida albicans & 15 & $9(60 \%)$ & $9(60 \%)$ & $3(20 \%)$ & $6(40 \%)$ & $6(40 \%)$ \\
\hline
\end{tabular}

$B C$ blood cultures, CoNS coagulase-negative staphylococci, neg negative, $P C R$ polymerase chain reaction (SeptiFast assay), pos positive, spp. species 
Table 3 Characteristics of patients with positive SF/BC result compared to those with negative SF/BC results

\begin{tabular}{|c|c|c|c|c|c|c|}
\hline & \multicolumn{3}{|l|}{ PCR (SeptiFast) } & \multicolumn{3}{|l|}{ Blood culture } \\
\hline & Negative $(n=237)$ & Positive $(n=42)$ & $P$-value & Negative $(n=232)$ & Positive $(n=47)$ & $P$-value \\
\hline Age [years] & $68.0[64.3-70.0]$ & $57[51.7-68.0]$ & 0.010 & $67[62.0-69.0]$ & 69 [59-69] & n.s. \\
\hline Male Gender [n, \%] & $161(68)$ & $30(71)$ & n.s. & $163(70)$ & $28(59)$ & n.s. \\
\hline \multicolumn{7}{|l|}{ Operative Procedure [n, \%] } \\
\hline CABG & $47(20)$ & $9(21)$ & n.s. & $46(20)$ & $10(21)$ & n.s. \\
\hline Isolated AVR & $8(3)$ & $1(2)$ & n.s. & $9(4)$ & $0(0)$ & n.s. \\
\hline Isolated MVS & $5(2)$ & $1(2)$ & n.s. & $4(2)$ & $2(4)$ & n.s. \\
\hline Combined procedures & $101(43)$ & $14(33)$ & n.s. & $99(43)$ & $16(34)$ & n.s. \\
\hline Aortic surgery & $25(11)$ & $4(10)$ & n.s. & $24(10)$ & $5(11)$ & n.s. \\
\hline Thoracic transplant & $13(5)$ & $4(10)$ & n.s. & $11(5)$ & $6(13)$ & n.s. \\
\hline Others & $38(16)$ & $9(21)$ & n.s. & $37(16)$ & $8(17)$ & n.s. \\
\hline CPB time [min.] & 177.0 [147.6-186.4] & 149.0 [116.6-207.8] & n.s. & 174.5 [147.2-185.0] & 161.0 [139.7-198.9] & n.s. \\
\hline Euro-Score II [\%] & $7.0[5.2-10.1]$ & $8.8[2.9-21.0]$ & n.s. & & $10.5[5.4-21.6]$ & n.s. \\
\hline TISS-28 on day of SF/BC & 19 [17-21] & 21 [15-22] & n.s. & 19 [17-21] & $18[14-21]$ & n.s. \\
\hline SAPS on day of SF/BC & $32[31-34]$ & 30 [27-35] & n.s. & $32[31-33]$ & $31[25-33]$ & n.s. \\
\hline Oxygenation $\left[\mathrm{mmHg} / \mathrm{FiO}_{2}\right]$ & 216.0 [196.3-230.4] & 240.0 [210.2-269.5] & n.s. & 220 [210.8-235.0] & 214.5 [195.7-282.7] & n.s. \\
\hline Heart frequency $\left[\mathrm{min}^{-1}\right]$ & $80.0[80.0-90.0]$ & $90.0[83.4-106.6]$ & n.s. & $90.0[80.0-90.0]$ & $90[90.0-100.0]$ & n.s. \\
\hline Body temperature $\left[{ }^{\circ} \mathrm{C}\right]$ & $37.6[37.4-37.8]$ & $37.6[37.1-37.9]$ & n.s. & $37.6[37.4-37.8]$ & $37.6[37.1-38.0]$ & n.s. \\
\hline RRT [n, \%] & $125(53)$ & $31(74)$ & 0.01 & $129(56)$ & $27(57)$ & n.s. \\
\hline \multicolumn{7}{|l|}{ Laboratory values } \\
\hline Serum lactate $[\mathrm{mg} / \mathrm{dll}]$ & $1.5[1.4-1.8]$ & $1.4[1.1-1.9]$ & n.s. & $1.5[1.4-1.7]$ & $1.4[1.1-2.5]$ & n.s. \\
\hline Bilirubin $[\mathrm{mg} / \mathrm{dl}]$ & $0.9[0.7-1.0]$ & $1.0[0.8-1.6]$ & n.s. & $0.9[0.7-1.0]$ & $0.9[0.5-1.2]$ & n.s. \\
\hline Leucocytes [/nl] & $14.0[13.0-15.0]$ & 12 [10.3-15.0] & 0.014 & $14.0[13.0-14.0]$ & $14.0[10.5-16.0]$ & n.s. \\
\hline Fibrinogen [mg/dl] & $464.0[430.0-496.7]$ & 525.0 [389.9-594.2] & n.s. & $472[433.8-503.9]$ & $504[438.5-544.9]$ & n.s. \\
\hline CRP $[\mathrm{mg} / \mathrm{dl}]$ & 14.4 [13.3-15.4] & $14.5[13.3-15.4]$ & 0.009 & 14.8 [13.7-15.9] & 15.2 [13.2-19.7] & n.s. \\
\hline PCT [ng/ml] & $3.1[2.3-4.7]$ & $6.6[2.7-16.4]$ & 0.015 & $3.4[2.5-4.9]$ & $2.2[1.3-3.8]$ & n.s. \\
\hline IL-6 [pg/ml] & $72.3[46.5-104.7]$ & 235.0 [83.5-1582.2] & 0.010 & 90.9 [61.7-144.3] & $141.0[46.6-240.2]$ & n.s. \\
\hline ICU stay [days] & 16 [15-19] & 22 [16-33] & 0.019 & 16 [15-19] & 18.5 [14.0-26.2] & 0.044 \\
\hline Hospital stay [days] & 23 [19-29] & 38 [25-59] & n.s. & $27[21-30]$ & 28 [20.7-42.7] & n.s. \\
\hline
\end{tabular}

AVR Aortic valve replacement, CABG coronary artery bypass grafting, $C P B$ Cardiopulmonary bypass, $C R P$ C-reactive protein, ICU intensive care unit, IL-6 interleukin $6, L T X$ lung transplant, MVS mitral valve surgery, n.s. not significant $(p>0.05), P C T$ procalcitonin, $P O D$ postoperative day, RRT renal replacement therapy, SAP Simplified Acute Physiology Score, TISS Therapeutic Intervention Scoring System, TVS tricuspid valve surgery

significantly higher $\mathrm{WBC}$ than patients with positive PCR (14.0 [13.0-15.0] vs. 12 [10.3-15.0], $p=0.014)$.

Patients with proven BSI in SF suffered from a more complicated postoperative course with prolonged ICU stay compared to SF-negative patients (ICU stay [days]: $26.1 \pm 16.2$ vs. $19.4 \pm 12.8, p=0.019)$. Comparing patients with positive and negative $\mathrm{BC}$, demographics, inflammatory markers and organ function did not differ whereas ICU-stay was longer in individuals with positive blood culture (16 days [15-19] vs. 18.5 [14.0-26.2], $p=0.044$ ).

Using ROC analysis, IL-6 (AUC 0.836 , sensitivity $78.6 \%$, specificity $75.9 \%$ for a cut-off $184 \mathrm{pg} / \mathrm{ml}$ ) as well as CRP (AUC 0.804 , sensitivity $71.4 \%$, specificity $75.9 \%$ for a cut-off $15.25 \mathrm{mg} / \mathrm{dl}$ ) showed the best predictive values for positive SF results (Fig. 2). In contrast, PCT and leukocytes were associated with poor predictive capacity.

\section{Impact of SF on antimicrobial therapy}

In eight out of 37 cases with pathogens solitarily identified by SF (21.6\%) microbiological diagnostic information led to therapy adaptations (Table 4). Only one of these pathogens was detected by blood culture whereas the other seven remained undetected with conventional diagnostics. In three patients, detection of A. fumigatus in SF led to the addition of antifungal therapy with voriconazole, in another three patients therapy was escalated with fluconazole and caspofungin, respectively. In one patient, vancomycin was added due to E. faecium identification in SF. 
$50 \%$ of patients could be discharged home whereas four patients died during the further hospital course.

\section{Discussion}

Our data demonstrate that the PCR-based SF test might represent a rational adjunct tool to the traditional $\mathrm{BC}$ method for rapid etiologic diagnosis of BSI in patients after cardiothoracic surgery. SF detects significantly more Gram-negative microorganisms than $\mathrm{BC}$, whereas $B C$ was superior regarding Gram-positive pathogens.

Early and reliable diagnosis of BSI and identification of bacteria and fungi is essential to initiate appropriate therapy in septic patients within one hour after sepsis as recommended by current guidelines $[8,16]$. For decades, detection of pathogen microorganisms in patients with suspected BSI was mainly based on BC. However, this procedure per se has two intrinsic limitations: Firstly, this method is limited by the delay of $12-36 \mathrm{~h}$ for positive signaling and up to 72 for identification of the pathogen and the antimicrobial susceptibility profile. In addition, approximately $30 \%$ of pathogens remain undetected by $\mathrm{BC}$ and the time to positivity is longer for some fastidious bacteria, anaerobes, and fungi or under antimicrobial therapy [17]. Thus, there is an urgent need to improve the diagnostic tools for an improved management of patients with BSI or sepsis. Molecular methods, in particular the LightCycler $\mathrm{SF}$, offer distinct advantages over blood cultures, including increased sensitivity and rapid diagnosis and is intensively investigated in clinical studies $[9,18]$. However, diagnostic accuracy and cost-effectiveness should be established before implementation in clinical practice.

A meta-analysis including a total of 34 studies enrolling 6012 patients with suspected sepsis reported a high specificity with a modest and highly variable sensitivity [19]. Recent studies revealed a low sensitivity of the PCR method accompanied with a limited utility for the diagnosis of healthcare-associated BSI in critical care patients [20]. In contrast, another study including 104 critically ill patients suffering from SIRS showed that in 25 cases $(16.9 \%, n=148)$ rapid identification of involved pathogens by multiplex-PCR led to adjustment of therapy [21]. A randomized controlled trial enrolling 78 adults with suspected pulmonary or abdominal infection demonstrated a significant reduction in the time required for initial pathogen identification with SF compared with BC [10]. Even in the context of an increasing number of MDR rapid detection of the respective microorganisms is essential [22]. Taken together, the results about the usefulness of the SF for rapid detection of BSI in critical ill patients are divergent.

Patients after cardiothoracic surgery significantly differ from other cohorts: The use of cardiopulmonary bypass leads to a damage of the gastrointestinal mucosa, subsequent increased permeability, possible bacteremia, and the activation of a self-limited inflammatory response. The incidence of fungal infections especially in transplant recipients is, due to immunosuppression, higher than in the general ICU population. Commonly used biomarkers for bacterial infection might not work properly in the cardiothoracic population [16, 23].

In accordance with previous studies, the results of the present study demonstrate that $\mathrm{SF}$, compared to $\mathrm{BC}$, provided a better management of contaminants and a lower contamination rate [24]. In respect of CoNS interpretation and discrimination in $\mathrm{BC}$ clinical judgment must be used due to a lack of objective criteria. In contrast, in SF an automated software is used to identify contaminants, which explains the lower rate of contaminants.

In accordance with recently published data, we observed a clear superiority of SF in detecting Gram-negative organisms compared to conventional BC [25]. The reason for this discrepancy is unclear. Recent studies could demonstrate that the superiority of SF over BC is particularly observed in patients with severe sepsis [26]. In our cohort, patients with Gram negative BSI had higher concentration of CRP, IL- 6 and PCT as well as a higher incidence of AKI with need for RRT compared to those with Gram-positive pathogens. Therefore, it might be hypothesized that SF is superior in detecting Gram-negative pathogens particularly in critically ill patients with severe infections.

BSI caused by Gram-negative bacteria is associated with a 7-fold increased risk of early mortality after cardiac surgery, compared with no BSI [5]. In contrast, BSI caused by Gram-positive bacteria other than $S$. aureus was only associated with a 2.2-fold increased risk of mortality [27]. Therefore, the early detection of Gram-negative bacteria in SF is of tremendous clinical relevance and might help to reduce mortality.

Since invasive fungal infections with Aspergillus are frequently associated with high morbidity and mortality, in particular immunocompromised patients benefit from prompt initiation of anti-fungal therapy [28]. However, the Surviving Sepsis Campaign does not recommend the routine use of empirical antifungals, based on the relatively low frequency of fungal causation of sepsis $(\sim 5 \%$ of cases), although this is likely to rise. In our cohort of patients, a notably but not significant higher number of Aspergillus amplicons were detected by PCR as compared with BC. SF could improve patient outcome as a result of rapid and accurate fungi detection and the consecutive timely initiation of appropriate therapy [29]. Hence, one important clinical impact of SF seems to be the identification of otherwise undetected fungal BSI.

However, SF was inferior to BC in detecting Grampositive bacteria including $S$. aureus, representing an important pathogen associated with high mortality. CoNS are a major constituent of human skin commensal flora, which were once considered relatively apathogen and a 


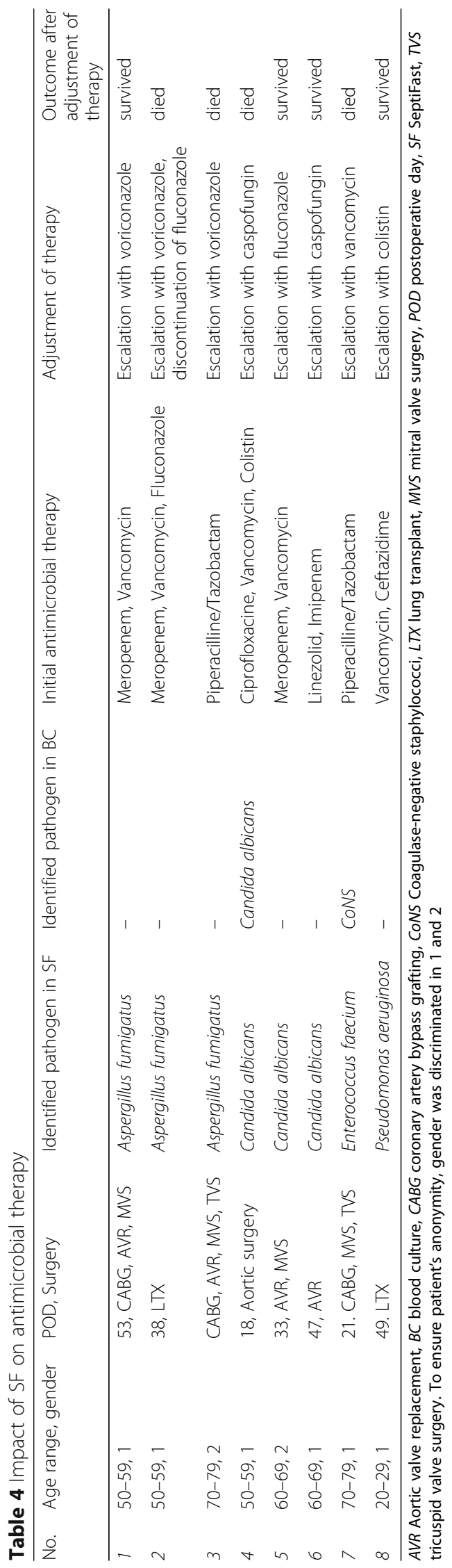


likely contaminant. But in patients with foreign materials (e.g. prosthetic valves, pacemakers, intravascular catheters) these organisms, due to their propensity to form a biofilm and to display resistance to multiple antibiotics, have increasingly been recognized as a cause of clinically significant infections. Thus, due to the significant number of infections that would be missed, SF could not replace blood culture for the identification of bloodstream infections. In addition, in SF pathogen identification is restricted to the 25 tested microorganisms and, moreover, susceptibility testing is not possible. In respect of the ongoing problem of multi drug resistance susceptibility testing is of increasing importance [30]. Therefore, SF cannot replace BC but represents an adjunct tool in combination with $\mathrm{BC}$.

Even though in our study antimicrobial therapy was escalated due to the results of SF in eight patients, no de-escalation was done. As most of our patients were already on broad spectrum antibiotics and several blood cultures were drawn before choosing SF as diagnostic tool, empirical antibiotic therapy was considered to be adequate for most of the pathogens detected in SF and de-escalation was not done due to the lack of susceptibility testing.

Recent studies could demonstrate that use of new PCR based technologies in the management of septic patients lead to a significant reduction in treatment costs with a an average net saving of $9970 €$ per patient [31]. This economic benefit is mainly based on shortening of intensive care unit stay and the use of fewer antibiotics. However, the costs of SeptiFast (approximately 200-300 USD) are high compared to Blood Culture (approximately 30 USD).

Mencacci investigated the predictive role of procalcitonin in patients with suspected sepsis for positive test results in BC and PCR and revealed an area under the curve of 0.927 for SF positivity [32]. When applying a cut-off value of $0.37 \mathrm{ng} / \mathrm{ml}$, the number of SF assays could be reduced by $53.9 \%$ with identifying $96.4 \%$ of pathogens. Leli et al. identified increased procalcitonin or white blood cells, fever $>38^{\circ} \mathrm{C}$, and low serum albumin as independent predictors of positive SF results in blood samples taken within $12 \mathrm{~h}$ after the onset of fever in 285 patients [33]. In our cohort, IL-6 as well as CRP was good predictors for SF positivity. Although PCT concentration are considered to be the gold standard of systemic inflammatory markers for diagnosis and evaluation of the treatment effectiveness, this marker only showed moderate predictive capabilities. The discrepancy could be due to the following: It is well established that aortic cross clamp and cardiopulmonary bypass related perioperative stress is associated with elevated PCT after cardiac surgery [34]. Several studies showed a poor correlation between elevated PCT concentration and bacterial infections or sepsis after major cardiac surgery [35]. Another aspect is that in our study 12 out of 47 positive SF results identified fungal pathogens. Thus, PCT as marker of bacterial infections is, anyway, not suitable for prediction of SF positivity in our cohort even more. Although the correlation of biomarkers and SF results are not very strong, in respect of the high costs of SF it might be helpful in the decision to perform SF or not.

\section{Limitations}

There are several potential limitations to this study. First, our study suffers from the general limitation of a single-center, retrospective investigation: the results may not be applicable to other clinical settings with different patient characteristics, resources, and laboratory procedures. In addition, due to the small number of specific pathogens, the power to detect a difference between the groups is limited.

In interpreting the results of this study heterogeneity in the methods of drawing blood samples for BC must be considered as a limitation. It could not be ensured that all collected samples complied with the guidelines for drawing blood samples for BC, what can affect both for sensitivity and specificity [36].

A major limitation is the fact that there were no predefined criteria for performing PCR e.g. presence of more than two SIRS criteria. The algorithms used in this study to differentiate between contamination and infection of BC and SF were not evaluated in the cardiothoracic population. Therefore, the reliability of this algorithm in this setting is uncertain. However, as there is no published algorithm for cardiothoracic patients, we modified the originally published algorithm to incorporate specific characteristics of our patient's cohort e.g. the presence of prosthetic heart valves or other extracorporeal devices.

Due to the retrospective nature of our study we could not ensure that the same blood sample was used for SF and $\mathrm{BC}$.

It has to be mentioned that the SF test is not available in the United States yet.

\section{Conclusion}

The PCR-based SF test might represent a valuable addition to the $\mathrm{BC}$ method for rapid etiologic diagnosis of bloodstream infections in patients after cardiothoracic surgery. This applies in particular for individuals with Gram-negative bacteremia. Since SF missed a certain number of Gram-positive pathogens, can only detect a limited number of pathogens and is unable to determine antibiotic susceptibility, it should always be used in conjunction with traditional blood culture methods. 


\section{Abbreviations}

AKI: Acute kidney injury; ANOVA: Analysis of variance; AUC: Area under the Curve; AVR: Aortic valve replacement; BC: Blood culture; BSI: Bloodstream infections; CABG: Coronary artery bypass grafting; CE: Conformité Européenne; CFU: Colony forming units; Cl: Confidence interval; CoNS: Coagulase-negative staphylococci; CPB: Cardiopulmonary bypass; CRP: C-reactive protein; CVC: Central venous catheter; DNA: Deoxyribonucleic acid; ICU: Intensive Care unit; IL-6: Interleukin 6; LTX: Lung transplant; LVAD: Left ventricular assist device; MDR: Multi drug resistance microorganisms; MVS: Mitral valve surgery; NI: Nosocomial infections; NPV: Negative predictive value; PCR: Polymerase chain reaction; PCT: Procalcitonin; POD: Postoperative day; PPV: Positive predictive value; ROC: Receiver operating characteristic; RRT: Renal replacement therapy; SF: SeptiFast; SIRS: Systemic inflammatory response syndrome; spp.: species; TVS: Tricuspid valve surgery

\section{Acknowledgements}

None.

\section{Funding}

This research received no specific grant from any funding agency in the public, commercial, or not-for-profit sectors.

\section{Availability of data and materials}

The data of the current study are available from the corresponding author on reasonable request.

\section{Authors' contributions}

KP, PMR, FD initiated the study. KP, PMR, JS, MT, HJ, FD contributed to the study design. KP, MD, FD acquired the data. KP, PMR, JS, FD analyzed and interpreted the data. KP, MD, SAP, FD drafted and revised the manuscript. MT, SAP, HJ critically revised the manuscript. All authors read and approved the final manuscript.

\section{Ethics approval and consent to participate}

The study was approved by the Institutional Review Board (No. 156541-BO) of the University Hospital Essen according to the Declaration of Helsinki. All patients had previously granted permission for use of their medical records for research purposes. Written informed consent was obtained within the pre-operative surgical written and verbal information conversation.

\section{Consent for publication}

Not applicable in that the manuscript does not contain data from any individual person.

The abstract has (in parts) already been published under license to BioMed Central Ltd. as an Open Access article distributed under the terms of the Creative Commons Attribution License (http://creativecommons.org/licenses/by/4.0). [1] The copyright holders (Pilarczyk et al. 2015) agreed to the publication in BMC Anesthesiology.

\section{Competing interests}

The authors declare that they have no competing interests.

\section{Publisher's Note}

Springer Nature remains neutral with regard to jurisdictional claims in published maps and institutional affiliations.

\section{Author details}

${ }^{1}$ Department of Intensive Care Medicine, imland Klinik Rendsburg managed by Sana $\mathrm{GmbH}$, Rendsburg, Germany. ${ }^{2}$ Department of Anaesthesiology and Intensive Care Medicine, University Hospital of Cologne, Kerpener Str. 62, 50937 Köln, Germany. '3Department of Thoracic and Cardiovascular Surgery, West German Heart and Vascular Center Essen, University Hospital Essen, University of Duisburg-Essen, Essen, Germany. ${ }^{4}$ Institute of Medical Microbiology, University Hospital Essen, University of Duisburg-Essen, Essen, Germany. ${ }^{5}$ Institute of Clinical Hygiene, Medical Microbiology and Infectiology, Paracelsus Medical University, Nuremberg, Germany.
Received: 12 November 2018 Accepted: 3 April 2019

Published online: 23 April 2019

\section{References}

1. Pilarczyk K, Rath P-M, Steinmann J, Benedik J, Wendt D, Dürbeck M, Jakob H, Dusse F. Multiplex PCR to diagnose bloodstream infections in patients after cardiothoracic surgery. Intensive Care Med Exp. 2015;3(Suppl. 1):A884.

2. Michalopoulos A, Geroulanos S, Rosmarakis ES, Falagas ME. Frequency, characteristics, and predictors of microbiologically documented nosocomial infections after cardiac surgery. Eur J Cardiothorac Surg. 2006;29(4):456-60.

3. Kollef MH, Sharpless L, Vlasnik J, Pasque C, Murphy D, Fraser VJ. The impact of nosocomial infections on patient outcomes following cardiac surgery. Chest. 1997;112(3):666-75.

4. De Santo LS, Bancone C, Santarpino G, Romano G, De Feo M, Scardone M, Galdieri N, Cotrufo M. Microbiologically documented nosocomial infections after cardiac surgery: an 18-month prospective tertiary care Centre report. Eur J Cardiothorac Surg. 2008;33(4):666-72.

5. Olsen MA, Krauss M, Agniel D, Schootman M, Gentry CN, Yan Y, Damiano RJ $J$ r, Fraser VJ. Mortality associated with bloodstream infection after coronary artery bypass surgery. Clin Infect Dis. 2008;46(10):1537-46.

6. Russotto V, Cortegiani A, Fasciana T, lozzo P, Raineri SM, Gregoretti C, Giammanco A, Giarratano A. What healthcare workers should know about environmental bacterial contamination in the intensive care unit. Biomed Res Int. 2017:2017:6905450.

7. Mammina C, Cala C, Bonura C, Di Carlo P, Aleo A, Fasciana T, Giammanco A, Group E-MW. Polyclonal non multiresistant methicillin resistant Staphylococcus aureus isolates from clinical cases of infection occurring in Palermo, Italy, during a one-year surveillance period. Ann Clin Microbiol Antimicrob. 2012;11:17

8. Dellinger RP, Levy MM, Rhodes A, Annane D, Gerlach H, Opal SM, Sevransky JE, Sprung CL, Douglas IS, Jaeschke R, et al. Surviving sepsis campaign: international guidelines for management of severe sepsis and septic shock: 2012. Crit Care Med. 2013:41(2):580-637.

9. Fenollar F, Raoult D. Molecular diagnosis of bloodstream infections caused by non-cultivable bacteria. Int J Antimicrob Agents. 2007;30(Suppl 1):S7-15.

10. Lee A, Mirrett S, Reller LB, Weinstein MP. Detection of bloodstream infections in adults: how many blood cultures are needed? J Clin Microbiol. 2007:45(11):3546-8.

11. Tafelski S, Nachtigall I, Adam T, Bereswill S, Faust J, Tamarkin A, Trefzer T, Deja M, Idelevich EA, Wernecke KD, et al. Randomized controlled clinical trial evaluating multiplex polymerase chain reaction for pathogen identification and therapy adaptation in critical care patients with pulmonary or abdominal sepsis. J Int Med Res. 2015:43(3):364-77.

12. The European Committee on Antimicrobial Susceptibility Testing (EUCAST). Breakpoint tables for interpretation of MICs and zone diameters. Corresponding current version, www.eucast.org. Accessed 05 Nov 2018.

13. Elzi L, Babouee B, Vogeli N, Laffer R, Dangel M, Frei R, Battegay M, Widmer AF. How to discriminate contamination from bloodstream infection due to coagulase-negative staphylococci: a prospective study with 654 patients. Clin Microbiol Infect. 2012;18(9):E355-61.

14. De Pauw B, Walsh TJ, Donnelly JP, Stevens DA, Edwards JE, Calandra T, Pappas PG, Maertens J, Lortholary O, Kauffman CA, et al. Revised definitions of invasive fungal disease from the European Organization for Research and Treatment of cancer/invasive fungal infections cooperative group and the National Institute of Allergy and Infectious Diseases mycoses study group (EORTC/MSG) consensus group. Clin Infect Dis. 2008:46(12):1813-21.

15. Lucignano B, Ranno S, Liesenfeld O, Pizzorno B, Putignani L, Bernaschi P, Menichella D. Multiplex PCR allows rapid and accurate diagnosis of bloodstream infections in newborns and children with suspected sepsis. J Clin Microbiol. 2011;49(6):2252-8.

16. Cortegiani A, Russotto V, Montalto F, Foresta G, Accurso G, Palmeri C, Raineri SM, Giarratano A. Procalcitonin as a marker of Candida species detection by blood culture and polymerase chain reaction in septic patients. BMC Anesthesiol. 2014;14:9.

17. Lamas CC, Eykyn SJ. Blood culture negative endocarditis: analysis of 63 cases presenting over 25 years. Heart. 2003;89(3):258-62.

18. Mauro MV, Cavalcanti P, Perugini D, Noto A, Sperli D, Giraldi C. Diagnostic utility of LightCycler SeptiFast and procalcitonin assays in the diagnosis of bloodstream infection in immunocompromised patients. Diagn Microbiol Infect Dis. 2012;73(4):308-11. 
19. Chang SS, Hsieh WH, Liu TS, Lee SH, Wang CH, Chou HC, Yeo YH, Tseng CP, Lee CC. Multiplex PCR system for rapid detection of pathogens in patients with presumed sepsis - a systemic review and meta-analysis. PLoS One. 2013:8(5):e62323.

20. Warhurst G, Dunn G, Chadwick P, Blackwood B, McAuley D, Perkins GD, McMullan R, Gates S, Bentley A, Young D, et al. Rapid detection of healthcare-associated bloodstream infection in critical care using multipathogen real-time polymerase chain reaction technology: a diagnostic accuracy study and systematic review. Health Technol Assess. 2015;19(35):1-142.

21. Lodes U, Bohmeier B, Lippert H, Konig B, Meyer F. PCR-based rapid sepsis diagnosis effectively guides clinical treatment in patients with new onset of SIRS. Langenbeck's Arch Surg. 2012;397(3):447-55.

22. Cortegiani A, Russotto V, Graziano G, Geraci D, Saporito L, Cocorullo G, Raineri SM, Mammina C, Giarratano A. Use of Cepheid Xpert Carba-R(R) for rapid detection of Carbapenemase-producing bacteria in abdominal septic patients admitted to intensive care unit. PLoS One. 2016;11(8):e0160643.

23. Heredia-Rodriguez M, Bustamante-Munguira J, Fierro I, Lorenzo M, JorgeMonjas P, Gomez-Sanchez E, Alvarez FJ, Bergese SD, Eiros JM, BermejoMartin JF, et al. Procalcitonin cannot be used as a biomarker of infection in heart surgery patients with acute kidney injury. J Crit Care. 2016;33:233-9.

24. Westh H, Lisby G, Breysse F, Boddinghaus B, Chomarat M, Gant V, Goglio A, Raglio A, Schuster H, Stuber F, et al. Multiplex real-time PCR and blood culture for identification of bloodstream pathogens in patients with suspected sepsis. Clin Microbiol Infect. 2009;15(6):544-51.

25. Burdino E, Ruggiero T, Allice T, Milia MG, Gregori G, Milano R, Cerutti F, De Rosa FG, Manno E, Caramello P, et al. Combination of conventional blood cultures and the SeptiFast molecular test in patients with suspected sepsis for the identification of bloodstream pathogens. Diagn Microbiol Infect Dis. 2014;79(3):287-92.

26. Cambau E, Durand-Zaleski I, Bretagne S, Brun-Buisson C, Cordonnier C, Duval X, Herwegh S, Pottecher J, Courcol R, Bastuji-Garin S, et al. Performance and economic evaluation of the molecular detection of pathogens for patients with severe infections: the EVAMICA open-label, cluster-randomised, interventional crossover trial. Intensive Care Med. 2017; 43(11):1613-25.

27. Garrouste-Orgeas M, Timsit JF, Tafflet M, Misset B, Zahar JR, Soufir L, Lazard T, Jamali S, Mourvillier B, Cohen Y, et al. Excess risk of death from intensive care unit-acquired nosocomial bloodstream infections: a reappraisal. Clin Infect Dis. 2006;42(8):1118-26.

28. Menzin J, Meyers JL, Friedman M, Perfect JR, Langston AA, Danna RP, Papadopoulos G. Mortality, length of hospitalization, and costs associated with invasive fungal infections in high-risk patients. Am J Health Syst Pharm. 2009;66(19):1711-7.

29. Thornton CR. Detection of invasive aspergillosis. Adv Appl Microbiol. 2010;70:187-216.

30. Russotto V, Cortegiani A, Graziano G, Saporito L, Raineri SM, Mammina C, Giarratano A. Bloodstream infections in intensive care unit patients: distribution and antibiotic resistance of bacteria. Infect Drug Resist. 2015;8:287-96.

31. Alvarez J, Mar J, Varela-Ledo E, Garea M, Matinez-Lamas L, Rodriguez J, Regueiro B. Cost analysis of real-time polymerase chain reaction microbiological diagnosis in patients with septic shock. Anaesth Intensive Care. 2012;40(6):958-63.

32. Mencacci A, Leli C, Cardaccia A, Meucci M, Moretti A, D'Alo F, Farinelli S, Pagliochini R, Barcaccia M, Bistoni F. Procalcitonin predicts real-time PCR results in blood samples from patients with suspected sepsis. PLoS One. 2012;7(12):e53279.

33. Leli C, Cardaccia A, D'Alo F, Ferri C, Bistoni F, Mencacci A. A prediction model for real-time PCR results in blood samples from febrile patients with suspected sepsis. J Med Microbiol. 2014;63(Pt 5:649-58.

34. Minami E, Ito S, Sugiura T, Fujita Y, Sasano H, Sobue K. Markedly elevated procalcitonin in early postoperative period in pediatric open heart surgery: a prospective cohort study. J Intensive Care. 2014;2(1):38.

35. Zhao D, Zhou J, Haraguchi G, Arai H, Mitaka C. Procalcitonin for the differential diagnosis of infectious and non-infectious systemic inflammatory response syndrome after cardiac surgery. J Intensive Care. 2014;2:35.

36. Tsalik EL, Jones D, Nicholson B, Waring L, Liesenfeld O, Park LP, Glickman SW, Caram LB, Langley RJ, van Velkinburgh JC, et al. Multiplex PCR to diagnose bloodstream infections in patients admitted from the emergency department with sepsis. J Clin Microbiol. 2010;48(1):26-33.

Ready to submit your research? Choose BMC and benefit from:

- fast, convenient online submission

- thorough peer review by experienced researchers in your field

- rapid publication on acceptance

- support for research data, including large and complex data types

- gold Open Access which fosters wider collaboration and increased citations

- maximum visibility for your research: over $100 \mathrm{M}$ website views per year

At BMC, research is always in progress.

Learn more biomedcentral.com/submissions 